\title{
DON-induced changes in bone homeostasis in mink dams
}

\author{
Ewa Tomaszewska ${ }^{1}$, Piotr Dobrowolski $^{2}$, Siemowit Muszyński ${ }^{3}$, \\ Krzysztof Kostro ${ }^{4}$, Iwona Taszkun ${ }^{5}$, Andrzej Żmuda ${ }^{4}$, \\ Tomasz Blicharski ${ }^{6}$, Monika Hułas-Stasiak ${ }^{2}$ \\ ${ }^{1}$ Department of Animal Physiology, ${ }^{4}$ Department of Epizootiology and Clinic of Infectious Diseases, \\ ${ }^{5}$ Sub-department of Clinical Diagnostics and Veterinary Dermatology, \\ Department and Clinic of Internal Medicine, Faculty of Veterinary Medicine, \\ ${ }^{3}$ Department of Physics, Faculty of Production Engineering, \\ University of Life Sciences in Lublin, 20-950 Lublin, Poland \\ ${ }^{2}$ Department of Comparative Anatomy and Anthropology, Faculty of Biology and Biotechnology, \\ Maria Curie-Skłodowska University, Lublin, 20-033 Poland \\ ${ }^{6}$ Chair and Department of Rehabilitation and Orthopaedics, \\ Medical University in Lublin, 20-090 Lublin, Poland \\ ewaRST@interia.pl
}

Received: May 6, 2017

Accepted: August 11, 2017

\begin{abstract}
Introduction: The aim of the study was to investigate the mechanical and geometric properties as well as bone tissue and mineral density of long bones in mink dams exposed to deoxynivalenol (DON) since one day after mating, throughout gestation (ca. $46 \mathrm{~d}$ ) and lactation to pelt harvesting. Material and Methods: Thirty clinically healthy multiparous minks (Neovison vison) of the standard dark brown type were used. After the mating, the minks were randomly assigned into two equal groups: nontreated control group and DON group fed wheat contaminated naturally with DON at a concentration of $1.1 \mathrm{mg} \cdot \mathrm{kg}^{-1} \mathrm{of}$ feed. Results: The final body weight and weight and length of the femur did not differ between the groups. However, DON contamination decreased mechanical endurance of the femur. Furthermore, DON reduced the mean relative wall thickness and vertical wall thickness of the femur, while vertical cortical index, midshaft volume, and cross-sectional moment of inertia increased. Finally, DON contamination did not alter bone tissue density, bone mineral density, or bone mineral content, but decreased the values of all investigated structural and material properties. Conclusion: DON at applied concentration probably intensified the process of endosteal resorption, which was the main reason for bone wall thinning and the weakening of the whole bone.
\end{abstract}

Keywords: mink, deoxynivalenol, bone, biomechanical parameters.

\section{Introduction}

Mycotoxins are low molecular weight substances, non-immunogenic, invulnerable to high temperatures, exhibiting carcinogenic, mutagenic, teratogenic, and oestrogenic activity. Among parasitic mycotoxinproducing fungi present in cereals, Aspergillus, Fusarium, and Penicillium cause common poisoning in fur animals. In Poland, mycotoxins like trichothecenes, deoxynivalenol (DON), and nivalenol produced by Fusarium culmorum and Fusarium gaminearum are the most serious problem. Their content is an important indicator of feed quality. Mycotoxins penetrate the body mostly via diet, rarely by inhalation or through skin and conjunctiva. They penetrate the placenta reaching the foetus or mother's milk $(1,2)$. Depending on the dose and production period during penetration, these mycotoxins may cause loss of appetite, impaired function of internal organs (liver and kidneys), fertility disorders, haematological problems, and general deterioration of animal health (16). Pigs fed DONcontaminated cereals at the level of $1 \mathrm{mg} \cdot \mathrm{kg}^{-1}$ demonstrate reduced voluntary feed intake (6). Similar observation was made for minks, where animals fed the 
diet contaminated with DON at level of $1.18 \mathrm{mg} \cdot \mathrm{kg}^{-1}$ consumed less feed than controls and demonstrated persistently reduced body weight (10). Thus, the Commission of the European Communities recommended guidance values for deoxynivalenol in products intended for animal feed (6). Maximum level for deoxynivalenol recommended in complementary and complete feedstuffs for pigs is $0.9 \mathrm{mg} \cdot \mathrm{kg}^{-1}$, for calves/lambs $2 \mathrm{mg} \cdot \mathrm{kg}^{-1}$, and for other animals $5 \mathrm{mg} \cdot \mathrm{kg}^{-1}(17)$.

A study performed on adult rabbits showed a significant impact of the mycotoxin on bone microstructure (7). Acute or chronic exposure of pregnant mothers to DON shows foetotoxic effects evidenced by skeletal ossification decrease and delayed foetal development (28). On the other hand, the influence of mycotoxin on bone metabolism in pregnant animals is still unknown. Also, the effect of DON on bone mineralisation and geometric and mechanical properties in minks has not been investigated so far. Thus, the aim of the present study was to investigate the possible toxic impact of mycotoxin on long bones of mink dams fed diet contaminated with DON at the level of $1.1 \mathrm{mg} \cdot \mathrm{kg}^{-1}$ since day one after mating throughout the gestation (ca. $46 \mathrm{~d}$ ) and lactation periods to pelt harvesting.

\section{Material and Methods}

Animals and experimental design. The study was carried out on a mink-breeding farm located in south Poland. Routine farm procedures were applied in the feeding, care, and breeding of the animals. In total, 30 clinically healthy multiparous minks (Neovison vison) of the standard dark brown type were used. They were held singly in separate cages under standard breeding/farming conditions and the natural photoperiod with free access to fresh water. The animals were fed well-balanced standard farm diet once a day. The mink dams were mated in March; next, after the delivery (May, June), the lactating dams were kept with their kits until weaning (after approximately two months, in September), after which they were held until pelt harvesting was performed in December/January. In accordance with the farm procedures and national Polish legislation, all dams were euthanised by carbon monoxide inhalation at pelt harvesting and skinned carcasses were delivered to the laboratory (8).

Diet and supplementation. After mating, the minks were randomly assigned to two equal groups: control group fed basal diet including wheat $(8 \%$ by mass) free of mycotoxins, beef liver, raw poultry byproducts, and fish, and experimental group (DON) fed the same basal diet, except wheat which was naturally contaminated with DON at a concentration of $1.1 \mathrm{mg} \cdot \mathrm{kg}^{-1}$ of grain. Contaminated fodder was given to the DON group since the first day after mating throughout the gestation (ca. $46 \mathrm{~d}$ ) and lactation periods to pelt harvesting. The level of DON contamination was chosen based on the literature ensuring normal pregnancy and maintaining the unreduced feed intake in mink dams (10).

Bone densitometry measurements. The measurement of bone tissue density (BTD) was performed with an AccuPyc 1330 pycnometer (Micromeritics, USA) as it was described previously $(22,26)$. The measurement of bone mineral density (BMD) and bone mineral content (BMC) was performed for the whole bone (as a total), and separately for the distal and proximal parts including both trabecular and cortical bone compartments, and the middle section of the midshaft. This analysis was performed using a DEXA Discovery densitometer (Hologic, USA). Particular regions of interest were defined manually (25).

Bone geometric properties. The micro-CT scans of midshaft part of the bone were obtained using the SkyScan 1072 system (Brüker, Belgium). Analysis of scans allowed determining the bone volume (BV) and tissue volume (TV), as well as the relative bone volume (BV/TV\%). Furthermore, the horizontal (M-L plane) external $\mathrm{H}$ and internal $\mathrm{h}$ as well as the vertical (A-P plane) external $\mathrm{B}$ and internal $\mathrm{b}$ diameters of the middiaphyseal cross-section of bone were measured. On the basis of the diameters, the following geometric properties were calculated: the mean relative wall thickness MRWT, the cortical cross-sectional area A, and the cortical index CI $(9,15)$. Moreover, as during the strength analysis the bone was loaded in the A-P plane, the vertical wall thickness $\mathrm{WT}_{\mathrm{v}}$ and vertical cortical index $\mathrm{CI}_{\mathrm{v}}$ were determined (15). To calculate the bone material properties, the cross-sectional moment of inertia $I_{x}$ and radius of gyration $R_{g}$ about $M-$ $\mathrm{L}$ axis were also calculated (15).

Bone strength analysis and calculation of bone structural traits. The bone length and weight were measured after removal of soft tissues. Relative bone weight was calculated as a ratio of organ weight and body weight. The mechanical properties of the femur were determined using the three-point bending test of bone mid-diaphysis performed on a Zwick Z010 universal testing machine (Zwick GmbH \& Company $\mathrm{KG}$, Germany), registering the relationship between force perpendicular to the longitudinal axis of the bone and the resulting displacement $(23,26)$. The distance between the supports was set at $40 \%$ of the total bone length. The measuring head loaded bone samples with a constant speed of $10 \mathrm{~mm} \cdot \mathrm{min}^{-1}$ until fracture (21). Determined structural properties were: the yield load $\mathrm{F}_{\mathrm{el}}$ as a maximal force under elastic (reversible) deformation of bone; the ultimate load $F_{m}$ as the force causing bone fracture; the stiffness $\mathrm{S}$ as the slope of the initial, elastic part of load-displacement curve, describing the bone resistance to deformation $(15,18)$. Determined material properties were: the Young's modulus of elasticity $\mathrm{E}$ describing bending resistance of the bone; yield strain $\varepsilon_{y}$ indicating the maximum 
strain which the bone can withstand for reversible deformation; bending moment described as a yield load adjusted to the bone length and indicating bone elastic load capability; yield stress $\sigma_{\mathrm{y}}$ reflecting the elastic strength of midshaft cortical bone, and ultimate stress indicating the maximum stress which bone can withstand in bending before fracture $(3,15)$. All traits were determined using the Origin 2016 software (OriginLab, USA).

Statistical analysis. Data were analysed using Statistica 12 software (StatSoft, Inc., USA). The distribution of the variables was tested for normality using the Shapiro-Wilk test. The comparison between normally distributed variables from the control and DON groups was carried out using Student's $t$ test. When variables were not normally distributed, comparisons were made using the Mann-Whitney U test. $\mathrm{P}<0.05$ was considered statistically significant for all tests. The data are presented as means with their respective standard deviations (mean $\pm \mathrm{SD}$ ).

\section{Results}

Body weight. The final mean body weight of the minks did not differ between both groups. The control minks and the DON-treated minks weighed $1716 \pm 192 \mathrm{~g}$ and $1719 \pm 183 \mathrm{~g}$, respectively.
Bone morphology, geometry, and mechanical properties. The diet containing DON-contaminated wheat did not influence the weight and length of the femur as well as relative bone weight, bone length/mass ratio, and the radius of gyration (Table 1). Consumption of DON-contaminated wheat resulted in the increased values of the horizontal external $(\mathrm{H})$ and internal (h) diameters while it did not affect either of the vertical diameters $(\mathrm{B}, \mathrm{b})$; however, a tendency to a wider vertical internal diameter was observed (Table 1). Furthermore, a decrease in the mean relative wall thickness and vertical wall thickness was noted in the DON group (Table 1). The DON-contaminated diet slightly increased the cross section area, and it was a statistically significant alteration (Table 1). Moreover, vertical cortical index, midshaft volume, and crosssectional moment of inertia of the femur also increased in the DON group (Table 1). BV/TV\% did not differ between both groups (data not shown).

None of the determined densitometric parameters (BTD, BMD, and BMC) differed between the groups (data not shown). However, DON given during the whole pregnancy, lactation, and after weaning until pelt harvesting decreased the values of all investigated structural and material properties determined during mechanical testing (Table 2).

Table 1. Geometric characteristics of the femur

\begin{tabular}{|c|c|c|c|}
\hline \multirow{2}{*}{ Dependent variable } & \multicolumn{2}{|c|}{ Group } & \multirow{2}{*}{ P value ${ }^{2}$} \\
\hline & $\operatorname{Control}^{1}(\mathrm{n}=15)$ & $\mathrm{DON}^{1}(\mathrm{n}=15)$ & \\
\hline \multicolumn{4}{|l|}{ Geometrical properties } \\
\hline Bone length, mm & $50.8 \pm 1.8$ & $50.8 \pm 1.9$ & n.s. \\
\hline Bone length/mass ratio, $\mathrm{mm} \cdot \mathrm{g}^{-1}$ & $26.1 \pm 2.2$ & $26.7 \pm 1.9$ & n.s. \\
\hline A-P plane external diameter $\mathrm{B}, \mathrm{mm}$ & $4.36 \pm 0.39$ & $4.36 \pm 0.08$ & n.s. \\
\hline A-P plane internal diameter $b, \mathrm{~mm}$ & $1.44 \pm 0.12$ & $1.67 \pm 0.07$ & n.s. \\
\hline M-L plane external diameter $\mathrm{H}, \mathrm{mm}$ & $3.49 \pm 0.16$ & $4.08 \pm 0.15$ & $* * *$ \\
\hline M-L plane internal diameter $\mathrm{h}, \mathrm{mm}$ & $1.39 \pm 0.24$ & $1.86 \pm 0.20$ & $* *$ \\
\hline Cross-sectional area $\mathrm{A}, \mathrm{mm}^{2}$ & $10.24 \pm 0.69$ & $11.60 \pm 0.85$ & $*$ \\
\hline Mean relative wall thickness MRWT & $1.87 \pm 0.54$ & $1.44 \pm 0.14$ & $* *$ \\
\hline Vertical wall thickness $\mathrm{WT}_{\mathrm{V}}, \mathrm{mm}$ & $1.48 \pm 0.06$ & $1.35 \pm 0.07$ & $* *$ \\
\hline Cortical index CI, \% & $57.2 \pm 3.7$ & $58.2 \pm 2.1$ & n.s. \\
\hline Vertical cortical index $\mathrm{CI}_{\mathrm{V}}, \%$ & $56.0 \pm 3.0$ & $61.9 \pm 4.6$ & $* *$ \\
\hline Midshaft volume, $\mathrm{mm}^{3}$ & $185 \pm 10$ & $235 \pm 5$ & $* *$ \\
\hline Cross-sectional moment of inertia $\mathrm{I}_{\mathrm{X}}, \mathrm{mm}^{4}$ & $12.4 \pm 0.9$ & $16.4 \pm 3.2$ & $* *$ \\
\hline Radius of gyration $\mathrm{R}_{\mathrm{g}}, \mathrm{mm}$ & $1.16 \pm 0.03$ & $1.18 \pm 0.07$ & n.s. \\
\hline
\end{tabular}

${ }^{1}$ Data are presented as mean \pm SD. ${ }^{2}$ Statistical significance: n.s. - not significant $\mathrm{P}>0.05$; $* 0.05>\mathrm{P}>0.01 ; * * 0.01>\mathrm{P}>0.001 ; * * * \mathrm{P}<0.001$ 
Table 2. Mechanical characteristics of the femur

\begin{tabular}{llll}
\hline \multirow{2}{*}{ Dependent variable } & \multicolumn{3}{c}{ Group } \\
\cline { 2 - 3 } & $\operatorname{Control}^{1}(\mathrm{n}=15)$ & $\mathrm{DON}^{1}(\mathrm{n}=15)$ & P value $^{2}$ \\
\hline Structural properties & & & \\
\hline Yield load $\mathrm{F}_{\mathrm{el}}, \mathrm{N}$ & $190.0 \pm 7.1$ & $87.5 \pm 7.6$ & $* *$ \\
\hline Ultimate load $\mathrm{F}_{\max }, \mathrm{N}$ & $229.8 \pm 14.7$ & $134.5 \pm 16.8$ & $* * *$ \\
\hline Stiffness $\mathrm{S}, \mathrm{N} \cdot \mathrm{mm}^{-1}$ & $213.8 \pm 27.5$ & $131.2 \pm 27.7$ & $* * *$ \\
\hline Material properties & & & \\
\hline Young's modulus of elasticity E, GPa & $3.02 \pm 0.43$ & $1.44 \pm 0.37$ & $* * *$ \\
\hline Yield strain $\varepsilon_{\mathrm{y}}, \%$ & $5.59 \pm 0.57$ & $4.34 \pm 0.71$ & $* *$ \\
\hline Bending moment M, N·m & $0.96 \pm 0.03$ & $0.44 \pm 0.04$ & $* *$ \\
\hline Yield stress $\sigma_{\mathrm{y}}, \mathrm{MPa}$ & $167.3 \pm 11.6$ & $60.5 \pm 9.7$ & $* *$ \\
\hline Ultimate stress $\sigma_{\mathrm{f}}, \mathrm{MPa}$ & $202.4 \pm 18.9$ & $92.9 \pm 16.6$ & $* *$ \\
\hline
\end{tabular}

${ }^{1}$ Data are presented as mean \pm SD. ${ }^{2}$ Statistical significance: $n$.s. - not significant $\mathrm{P}>0.05$; $* 0.05>\mathrm{P}>0.01 ; * * 0.01>\mathrm{P}>0.001 ; * * * \mathrm{P}<0.001$

\section{Discussion}

Acute or chronic toxicosis is caused by feed containing toxins produced by saprophytic or phytopathogenic fungi or moulds during their growth. Mycotoxicosis may not be diagnosed over long time. It is seasonal and depends on many factors; firstly, genetic, e.g. species and breed, and, secondly, physiological (age, nutrition, intestinal microflora, infection, and parasitism) and environmental (climatic conditions or husbandry) (4). As regards the spread of mycotoxicosis, the fact that it is not transferable from one animal to another is less important. Mycotoxicosis reduces feed intake and leads to loss of body weight over time $(16,20)$.

However, our present study showed that the dams consuming DON-contaminated feed did not lose their body weight. Similar observation was made by Gibson et al. (10), who found no weight loss in minks fed DON-contaminated feed at concentrations up to $0.62 \mathrm{mg} \cdot \mathrm{kg}^{-1}$. Opposite effect was noted in our earlier study with mink dams fed a diet containing DONcontaminated grains at the concentration of $3.7 \mathrm{mg} \cdot \mathrm{kg}^{-1}$, which resulted not only in growth inhibition and weight loss, but also led to reduction of bone length (24). It is suggested that minks are close in sensitivity to DON to swine, for which guidance level for mycotoxins in feed was set at $0.9 \mathrm{mg} \cdot \mathrm{kg}^{-1}(10,17)$. Thus, it might be speculated that the feed containing wheat naturally contaminated with DON at a concentration of $1.1 \mathrm{mg} \cdot \mathrm{kg}^{-1}$ could significantly influence body weight reduction if given to dams from the basic herd, which are held for three years. However, a more detailed comparison of findings observed in this study with those from other scientific reports is somewhat difficult because no studies on the effects of DON at similar concentration are available with reference to fur animals.

Yet, the low oral dose of DON used in the present study caused slight gastroenteritis with no visible acute symptoms, which might not have significantly influenced final body weight, but was sufficient to trigger malnutrition, resulting in altered bone homeostasis and decreased mechanical endurance. Bone tissue is characterised by high mechanical strength, because it contains up to $70 \%$ minerals, mainly in the form of hydroxyapatite. The knowledge about the influence of mycotoxins on the mechanical endurance of bones, especially in fur animals, is still insufficient. The study conducted on chickens with ochratoxin and aflatoxin showed that aflatoxin significantly influences bone metabolism (12). It has been found that one of the effects of mycotoxin action is disturbance of calcium and phosphorus metabolism (20) or absorption of calcium in the small intestine (19). Impairments in calcium metabolism caused by DON may be partially related to development of a secondary deficiency in vitamin $\mathrm{D}_{3}(21)$, which plays an essential role in prevention of bone diseases like dyschondroplasia (26). However, the mechanism of this mycotoxin's action has not been explained yet.

The mechanical endurance depends on the body and bone mass, geometry, microarchitecture, and bone quality as a relationship of the mineralisation and bone matrix. Our study with mink dams exposed to DON at the concentration of $3.7 \mathrm{mg} \cdot \mathrm{kg}^{-1}$ showed that mycotoxins reduced geometric and mechanical endurance as well as bone mineral density (24). However, neither BMD, as an important indicator of bone strength, nor BTD differed between DON-treated and non-exposed dams in the present study. This may indicate that bone mineralisation was not disturbed in 
the minks. Histomorphometic parameter of trabecular bone describing its microarchitecture (BV/TV\%) also remained unchanged. It could suggest that reduced endurance was independent of trabecular bone structure.

The size and shape of the bone change with age, because bone is being constantly remodelled. Moreover, long bone increases its thickness due to formation of new layers on the periosteal side in a process called apposition. On the other hand, the bone remodelling process also occurs on the endosteal side. Bone remodelling on the side of the bone marrow cavity and the apposition influence the cross section area of the long bone midshaft. If bone resorption is greater than synthesis, the endosteal resorption is observed as enlargement of the marrow cavity with accompanying wall thinning of the bone, as it was observed in the dams in the present experiment. The alteration in bone metabolic activity on the surface of the periosteum and endosteum was well visible in DON-exposed minks, manifesting the change of the horizontal internal and external diameters of the middiaphyseal cross-section of bone (Table 1). The increase in both internal diameters may indicate that the process of endosteal resorption could be more intensive than periosteal apposition. These disturbances resulted in the alteration of bone geometry, as indicated by the reduced values of MRWT and $\mathrm{CI}_{\mathrm{v}}$. As a result, geometric index determining the bone material traits, namely cross-sectional moment of inertia Ix, significantly increased. This might be the main cause of the reduced mechanical endurance of the femur.

However, the significantly reduced value of yield strength could have resulted from impaired synthesis of collagen or other organic components of bone tissue, as bone elasticity depends also on the functionality of organic matrix (11). It is well known that the connective tissue strength is based on the orientation, density, and length of both collagen fibrils and fibres, and there is a functional link between the skeletal muscle cell and the bone (13). Furthermore, the force transmission of the muscle-tendon complex on bone depends on the structural integrity between muscle fibres and the extracellular matrix (14). Malnutrition resulting from the presence of mycotoxicosis in the diet could influence the management of the ions homeostasis in the organism; it could cause weakness of muscles and finally reduced mechanical endurance.

In summary, this study showed that DON contamination at the dose of $1.1 \mathrm{mg} \cdot \mathrm{kg}^{-1} \mathrm{did}$ not influence body weight, bone mass and length, as well as BMD and BMC of the femur in mink dams. Since DON probably intensified the process of endosteal resorption, administration thereof resulted in reduced values of geometrical parameters and mechanical endurance of the femur. The mechanism of the changed bone metabolism in animals fed DON-contaminated diet, not only in dams, should be investigated further.
Conflict of Interests Statement: The authors declare that there is no conflict of interests regarding the publication of this article.

Financial Disclosure Statement: The study was supported by the funds of the Polish Ministry of Science and Higher Education.

Animal Rights Statement: The experimental procedures used throughout the study were approved by the Local Ethics Committee on Animal Experimentation of University of Life Sciences of Lublin, Poland.

\section{References}

1. Belmadani A., Tramu G.: Regional selectivity to ochratoxin A, distribution and cytotoxicity in rat brain. Arch Toxicol 1998, 72, 656-662.

2. Blank R., Rolfs J.P., Südekum K.H., Frochlich A.A., Marquardt R.R., Wolfram S.: Effects of chronic ingestion of ochratoxin A on blood vessels and excretion of the mycotoxin in sheep. J Agricult Food Chem 2003, 51, 6899-6905.

3. Blicharski T., Tomaszewska E., Dobrowolski T., Hułas-Stasiak M., Muszyński S.: A metabolite of leucine ( $\beta$-hydroxy- $\beta$ methylbutyrate) given to sows during pregnancy alters bone development of their newborn offspring by hormonal modulation. PLoS One 2017, 12, e0179693, doi: 10.1371/journal.pone.0179693.

4. Bryden W.L.: Mycotoxin contamination of the feed supply chain: implications for animal productivity and feed security. Anim Feed Sci Technol 2012, 173, 134-158.

5. Commission Recommendation 2006/583/EC of 17 August 2006 on the prevention and reduction of Fusarium toxins in cereals and cereal products (Text with EEA relevance). Off J EU 2006, L234/35.

6. Döll S., Dänicke S.: The Fusarium toxins deoxynivalenol (DON) and zearalenone (ZON) in animal feeding. Prev Vet Med 2011, 102, 132-145.

7. Duranova H., Kovacova V., Babosova R., Omelka R., Adamkovicova M, Grosskopf B., Capcarova M., Martiniakova M.: Sex-related variations in bone microstructure of rabbits intramuscularly exposed to patulin. Acta Vet Scand 2015, 57, 50.

8. European Council: The European Communities Council Directive 98/58/EC of 20 July 1998 concerning the protection of animals kept for farming purposes. Off J EU 1998, L2331, 23-27.

9. Ferretti J.L., Capozza R.F., Mondelo N., Zanchetta J.R.: Interrelationships between densitometric, geometric and mechanical properties of rat femora: inferences concerning mechanical regulation of bone modelling. J Bone Min Res 1993, 8, 1395-1399.

10. Gibson M.K., Bursian S.J., Aulerich R.J.: Effects of deoxynivalenol on feed consumption and body weight gain in mink (Mustela vision). Bull Environ Contam Toxicol 1993. 51, 6-11.

11. Hayes W.C., Gerhart T.N.: Biomechanics of bone: applications for assessment of bone strength. In: Bone and mineral research, edited by W.A. Peck, Elsevier Science Publisher, Amsterdam, 1985, pp. 259-294.

12. Huff W.E., Doerr J.A., Hamilton P.B., Hamann D.D., Peterson R.E., Ciegler A.: Evaluation of bone strength during aflatoxicosis and ochratoxicosis. Appl Environ Microbiol 1980, 40, 102-107.

13. Jonas J., Burns J., Abel E.W., Cresswell M.J., Strain J.J., Paterson C.R.: Impaired mechanical strength of bone in 
experimental copper deficiency. Ann Nutr Metab 1993, 37, 245-252.

14. Kjaer M.: Role of extracellular matrix in adaptation of tendon and skeletal muscle to mechanical loading. Physiol Rev 2004, 84, 649-698.

15. Muszyński S., Kwiecień M., Tomaszewska E., Świetlicka I., Dobrowilski P., Kasperek K., Jeżewska-Witkowska G.: Effect of caponization on performance and quality characteristics of long bones in Polbar chickens. Poult Sci 2017, 96, 491-500.

16. Pestka J.J.: Deoxynivalenol: toxicity, mechanisms and animal health risks. Anim Feed Sci Technol 2007, 137, 283-298.

17. Pinotti L., Ottoboni M., Giromini C., Dell'Orto V., Cheli F.: Mycotoxin contamination in the EU feed supply chain: A focus on cereal byproducts. Toxins 2016, 8, 45.

18. Regmi P., Smith N., Nelson N., Haut R.C., Orth M.W., Karcher D.M.: Housing conditions alter properties of the tibia and humerus during the laying phase in Lohmann white Leghorn hens. Poult Sci 2016, 95, 198-206.

19. Sergeev I.N., Kravchenko L.V., Piliia N.M., Batukhanov A.B., Sobolev V.S., Kuz'mina E.E., Iakushina L.M., Spirichev V.B., Tutel'ian V.A.: The effect of the trichothecene mycotoxin deoxynivalenol (vomitoxin) on calcium homeostasis, vitamin D metabolism and receptors in rats. Vopr Med Khim 1990, 36, 26-29.

20. Smith T.K. Effect of dietary calcium, phosphorus and vitamin D on zearalenone toxicosis in rats. Can J Anim Sci 1981, 61, 191-197.

21. Sliwa E.: 2-Oxoglutaric acid administration diminishes fundectomy-induced osteopenia in pigs. J Anim Physiol Anim Nutr (Berl) 2010, 94, 86-95.
22. Tomaszewska E., Dobrowolski P., Kostro K., Jakubczak A., Taszkun I., Jaworska-Adamu J., Żmuda A., Rycerz K., Muszyński S.: The effect of HMB and 2-Ox administered during pregnancy on bone properties in primiparous and multiparous minks (Neivison vison). Bull Vet Inst Pulawy 2015, 59, 563-568.

23. Tomaszewska E., Dobrowolski P., Siwicki A.K.: Maternal treatment with dexamethasone at minimal therapeutic doses inhibits neonatal bone development in a gender-dependent manner. Livest Sci 2012, 146, 175-182.

24. Tomaszewska E., Muszyński S., Dobrowolski P., Kostro K., Taszkun I., Żmuda A., Blicharski T., Kędzia P.: Bentonite diminishes DON-induced changes in bone development in mink dams. J Vet Res 2016, 60, 349-355.

25. Tomaszewska E., Kwiecień, M., Muszyński S., Dobrowolski P., Kasperek K., Blicharski T., Jeżewska-Witkowska G., Grela E.R.: Long-bone properties and development are affected by caponisation and breed in Polish fowls. Br Poult Sci, doi: 10.1080/00071668.2017.1280770.

26. Tomaszewska E., Dobrowolski P., Świetlicka I., Muszyński S., Kostro K., Jakubczak A., Taszkun I., Żmuda A., Rycerz, K., Blicharski T., Jaworska-Adamu J.: Effects of maternal treatment with $\beta$-hydroxy- $\beta$-metylbutyrate and 2 -oxoglutaric acid on femur development in offspring of minks of the standard dark brown type. J Anim Physiol Anim Nutr 2017, doi: 10.1111/jpn.12742.

27. Whitehead C.C.: The role of vitamin D metabolites in the prevention of tibial dyschondroplasia. Anim Feed Sci Technol 1995, 53, 205-210.

28. Zaho Y., Zhu X., Wu H., Zhuang D., Yu G., Li X., Feng Li F., $\mathrm{Yu}$ A. Evaluation of fetal skeletal malformations in deoxynivalenol-treated mice using microarray analysis. Arch Environ Contam Toxicol 2012, 63, 445-452. 